УДК 398

ББК $82.3(2)$

\section{У ИСТОКОВ РУССКОЙ МУЗЫКАЛЬНОЙ ФОЛЬКЛОРИСТИКИ СИБИРИ (20-40-е гг. $X X$ в.)}

(C) 2019 г. Н.А. Урсегова

Новосибирский государственный педагогический университет, Новосибирск, Россия

Дата поступления статьи: о3 апреля 2019 г. Дата публикации: 25 декабря 2019 г.

DOI: IO.22455/2500-4247-20I9-4-4-280-293

Аннотация: Статья посвящена изучению советского этапа предыстории сибирской музыкальной фольклористики с точки зрения выявления новых, равноценных дореволюционным нотных собраний на основе анализа фольклористических источников, оценки их исторического значения. Малочисленность записей и публикаций мелодий народных песен вызвала в середине 20-х гг. XX в. обсуждение проблем музыкальной этнографии на страницах журнала «Сибирская живая старина». В период с 1926 по 1944 гг. библиография русской сибирской музыкальной фольклористики, к сожалению, не пополнилась сколько-нибудь ценными песенными сборниками (исключение составляют публикации дореволюционных записей Н.П. Протасова в 1926 г.). Особую ценность имеет научно-теоретическая и практическая (собирательская) деятельность Г.С. Виноградова, в работах которого закладываются теоретические основы современного, так называемого «типологического», направления научных исследований сибирской музыкальной фольклористики. Положительно оценен методологический подход Г.С. Виноградова по вопросам собирания сведений о сибирских музыкантах и музыкальном исполнительстве при активном привлечении к этой работе этнографов, не имеющих специального музыкального образования.

Ключевые слова: музыкальный фольклор, этнография, история, нотная запись, собирание, публикация, фольклорное музыкальное творчество, музыкальное исполнительство.

Информация об авторе: Наталья Александровна Урсегова - кандидат искусствоведения, доцент кафедры народной художественной культуры и музыкального образования Института культуры и молодежной политики, ФГБОУ ВО «Новосибирский государственный педагогический университет», ул. Вилюйская, д. 28, 630І26 г. Новосибирск, Россия.

E-mail: urseg@yandex.ru

Для цитирования: Урсегова Н.А. У истоков русской музыкальной фольклористики Сибири (20-40-е гг. XX в.) // Studia Litterarum. 2019. Т. 4, № 4. С. 280-293. DOI: $10.22455 / 2500-4247-2019-4-4-280-293$ 


\title{
AT THE ORIGINS OF THE RUSSOPHONE MUSICAL FOLKLORE OF SIBERIA (1920s-1940s)
}

This is an open access article distributed under the Creative Commons Attribution 4.0 International (CC BY 4.0)

\author{
(C) 2019. N.A. Ursegova \\ Institute of Culture and Youth Policy, Federal State \\ Budgetary Educational Institution of Higher Education \\ "Novosibirsk State Pedagogical University", \\ Novosibirsk, Russia \\ Received: April 03, 2019 \\ Date of publication: December 25, 2019
}

\begin{abstract}
The author examines the Soviet stage of the prehistory of Siberian musical folklore. The aim of the study is to reveal new musical collections that would be equivalent to their pre-revolutionary predecessors, analyze folklore sources, and evaluate their historical significance. Small number of records and publication of folk songs entailed a discussion of the problems of musical ethnography in the pages of the magazine Sibirskaya Zhivaya Starina in the mid-I920s. Unfortunately, in the period from 1926 to I944, no valuable song collections (with the exception of the publication of prerevolutionary notes by N.P. Protasov) were added to the bibliography of Russian Siberian folklore music. Of special value is theoretical and practical (collecting) activity of G.S. Vinogradov. His works lay a theoretical foundation for the modern, the so-called "typological" trend in the study of Siberian folklore. The article accredits Vinogradov's methodological approach to the collection of information about Siberian musicians and musical performance that engages ethnographers who do not have professional musical education.
\end{abstract}

Keywords: musical folklore, ethnography, history, musical notation, collection, publication, folklore musical creativity, musical performance.

Information about the author: Natalya A. Ursegova, $\mathrm{PhD}$ in Art History, Associate Professor at the Department of Folk Artistic Culture and Music Education, Institute of Culture and Youth Policy, Federal State Budgetary Educational Institution of Higher Education “Novosibirsk State Pedagogical University,” Vilyuiskaya 28, 630126 Novosibirsk, Russia.

E-mail: urseg@yandex.ru

For citation: Ursegova N.A. At the Origins of the Russophone Musical Folklore of Siberia (I920s-I94OS). Studia Litterarum, 2019, vol. 4, no 4, pp. 280-293. (In Russ.) DOI: Io.22455/2500-4247-20I9-4-4-280-293 
История сибирской музыкальной фольклористики в настоящее время еще не написана, хотя все необходимые для этого предпосылки созданы: собраны и опубликованы многочисленные фольклорные собрания, накоплены уникальные архивные материалы, написаны разнообразные научные работы. Однако всё еще малоизученным (и не до конца оцененным) является значительный хронологический отрезок времени, охватывающий период c I9I7 по I944 гг. - советский этап предыстории сибирской музыкальной фольклористики.

Нельзя не согласиться с авторитетным мнением новосибирского этномузыколога Н.В. Леоновой, которая доказательно относит к ранним источникам, составившим предысторию сибирской музыкальной фольклористики, нотные собрания русских народных песен сибирского бытования, опубликованные в конце XIX - начале XX вв. в дореволюционных трудах тобольского краеведа М. Костюриной, сибирского фольклориста Н. Протасова, политического ссыльного В. Бартенева [7, с. 88].

Непосредственно историю записи и публикации музыкального фольклора сибирских переселенцев Н.В. Леонова предлагает начинать с середины 40-х гг. XX в.: опираясь на публикации 2-й половины XX - начала $\mathrm{XXI}$ вв., она выделяет три периода в новой истории записи музыкального фольклора сибирских переселенцев, характеризует основные черты каждого из них, выявляет наиболее значимые нотные публикации сибирских песен [7, с. 88].

Однако малоизученным, по нашему мнению, является почти тридцатилетний отрезок времени после І9I4 г. - года публикации наиболее позднего по времени дореволюционного сибирского песенного издания 
В. Бартенева ${ }^{\mathrm{I}}$ - и до 1945 г. - времени публикации первого современного советского нотного фольклорного сборника, составителями которого были новосибирцы Л. Кондырев и А. Новиков².

В этой связи представляется целесообразным сфокусировать внимание на наименее освещенный в науке предыстории сибирской музыкальной фольклористики советского периода 20-40-х гг. XX в. в источниковедческом ракурсе, что позволит оценить историческое значение опубликованных нотных собраний этого периода времени в сравнении с дореволюционными, более подробно осветить научно-теоретическую и практическую (собирательскую) деятельность фольклористов-сибиряков, внесших значительный вклад в процесс становления русской музыкальной фольклористики сибирского региона.

Важное место в предыстории русской сибирской музыкальной фольклористики занимает исследовательская (научно-теоретическая), организационно-методическая и собирательская деятельность Г.С. Виноградова - выдающегося российского ученого, сфера научных интересов которого традиционно ассоциируется в фольклористической науке с этнопедагогической проблематикой, но ей не ограничивается.

В г923 г. в своей по сути программной статье «Этнография и современность», опубликованной в первом выпуске журнала «Сибирская живая старина», он декларирует необходимость фиксации тех изменений, что происходят с традиционным фольклором в условиях революционного времени. Он обращает внимание на то, что «в области народной песни всякие изменения в жизни находят довольно быстрое отражение» [2, с. 9]. Далее он пишет: «До сих пор не обращено достаточного внимания на граммофон. Было бы очень важно обследовать роль граммофонных пластинок в деле увеличения и изменения народного песенного репертуара, на изменения, произошедшие в исполнении полученных этим путем песен и т. д.» [2, с. 9].

Ученый предлагает также изучать песенное творчество религиозного содержания в условиях борьбы советского государства с религией, выявить степень влияния на песенный репертуар лубочных изданий-песенников -

I Обдорские песни: (С нотами) / В.В. Бартенев. Архангельск: Губ. тип., I9I4. I7 c. (Перепеч. из № 20 «Изв. Арханг. о-ва изуч. Рус. Севера» за 1914 г.). Обдорские песни записаны в с. Обдорск Березовского округа Тобольской губернии.

2 Песни Сибири / сост. Л. Кондырев и А. Новиков; ред. текста Е. Стюарт; ред. муз.

В. Денбский. Новосибирск. 1945.65 с. 
картинок с текстами народных песен, обратить внимание на проникновение в репертуар деревенских певцов солдатских песен, которые «активно распевались мужчинами и женщинами на мирных праздничных гулянках» [2, с. 9].

Кроме того, ученый настаивает на необходимости записи городской и деревенской частушки - жанра относительно новой формации: «...она живет десятки лет, видоизменяется, и признаков ее вымирания мы не замечаем» [2, с. го]. Ученый особо выделяет распространившиеся среди молодежи частушки политического содержания.

Таким образом, по мнению Г.С. Виноградова внимание исследователей и собирателей должны привлекать не только старые (традиционные) жанры и формы, но и современные; чтобы их зафиксировать, необходимо торопиться наблюдать их в бурной динамике настоящего момента.

Первая публикация фольклорной мелодии осуществлена Г.С. Виноградовым в г923 г.: в работе «Смерть и загробная жизнь в воззрениях русского старожилого населения Сибири» находим мелодию надмогильного вопля невесты [5]. В следующем I924 г. Г.С. Виноградов публикует важную с методологической точки зрения работу «Детский народный календарь (Из очерков по детской этнографии)» [3], в которой он не только впервые в отечественной науке раскрывает «объем и содержание понятия детская этнография», но и формулирует новую научную проблему из области этномузыкологии - необходимость «изучения детского фольклора (в узком значении этого слова) и детского музыкального творчества: построить ткань звучаний, интонировать звучания» [3, с. 82].

В приложение к своей публикации Г.С. Виноградов размещает нотные образцы трех детских мелодий: «Дождик, припусти», «Коршун», «Колыбельная». Авторство нотировок установить не представляется возможным. Однако следует отметить, что запись текстов нотированных песен выполнена весьма корректно: она отражает диалектные особенности произнесения (местный говор). Нотировки песен представляют собой одно- и двухголосные образцы. Нотирование песен выполнено полностью - от начала и до конца словесного текста, демонстрирует музыкальную вариативность песенных текстов. Единственное, чего недостает этим нотировкам, в сравнении с современными записями, - вертикального синтаксического ранжира, позволяющего разглядеть структурную организованность музыкально-фольклорного текста. 


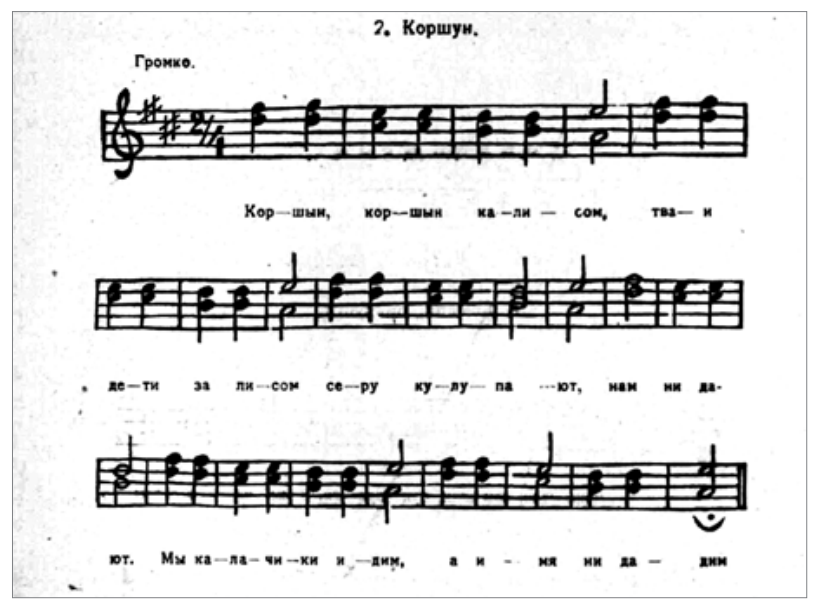

Пример I - «Коршун» [3, с. 88]

Example I - "Hawk” [3, p. 88]

Г.С. Виноградов, как и другие сибирские фольклористы, отчетливо осознает необходимость научного обеспечения музыкально-этнографической собирательской работы в Сибири особыми программами-вопросниками. Так, в 1925 г. в журнале «Сибирская живая старина» были опубликованы Тезисы выступления И.С. Хромовских на I Восточно-сибирском краеведческом съезде, посвященные актуальным проблемам записи песен [І2, с. 69]. По мнению автора, для того чтобы «собирание песен было планомерным и более продуктивным, необходимо: а) объединить собирателей; б) обеспечить возможность собирания с материальной стороны пособиями, руководствами, техническими материалами» [І2, с. 69].

В том же году в Киеве на украинском языке была опубликована программа К.В. Квитки по изучению деятельности и быта профессиональных народных певцов и музыкантов Украины» [6], а уже в следующем І925 г. в журнале «Сибирская живая старина» Г.С. Виноградов размещает на нее свою восхищенную рецензию «Новая программа по музыкальной этнографии» [I].

Программа К.В. Квитки стала для Г.С. Виноградова по-настоящему ценной, так как отвечала на принципиальный вопрос: как помочь этнографам без специального музыкального образования грамотно организовать и провести работу по собиранию сибирского музыкального фольклора и сведений о бытовании народной музыки, о музыкантах? 
Г.С. Виноградов отлично понимал, что «область музыкального искусства не сводится к пению и песне, что, кроме части вокальной, в эту область надо включить и часть музыкальную в узком понимании этого слова» [I, c. 388]. По мнению Виноградова, «в этнографической литературе очень мало данных для суждения об условиях бытования песни и пения в недалеком прошлом и текущем настоящем, о народных певцах, образе их жизни, певческой школе, репертуаре и т. д.» [І, с. 388].

Поэтому для изучения мало освещенных фактами очень важных вопросов музыкальной этнографии, по мысли Виноградова, должны быть разработаны особые программы-вопросники с краткими комментариями по аналогии с программой К. Квитки.

Г.С. Виноградов пишет: «Труд Кл. Квитки имеет немаловажное значение и для этнографов, ведущих работу среди русского населения Сибири. Не говоря уже о том, что он - в несколько измененном, так сказать, приспособленном, виде - может оказаться весьма полезным при изучении вопросов музыкальной этнографии старожилового населения страны, следует иметь в виду, что и не подвергаясь какой-либо переработке, программа эта может (и должна) быть использована сибирскими этнографами» [I, с. 390].

Взгляд на фольклор как на явление современной народной жизни, живое и развивающееся, подсказал Г.С. Виноградову новые актуальные задачи сибирской музыкальной фольклористики: І) «изучить судьбу “хохлацкой” народной музыки и пения» на территориях, где украинцы проживают автономно (в южной части Акмолинской области, по берегам Амура и в Приморье) и 2) изучить специфику музыкального творчества и уклада народной жизни переселенцев из Малороссии, проживающих «среди сел и деревень старожилого населения Средней Сибири <...> занятых 20-30 лет назад» [г, с. 390].

Таким образом, Г.С. Виноградову принадлежит большая заслуга в постановке вопроса о фольклорных изучениях культуры славянских переселенцев из Малороссии, проживающих на территории Сибири как обособленно, так и чересполосно, в тесном взаимодействии со старожильческим населением. Г.С. Виноградов, опережая время, сформулировал (на основе изучения музыкального творчества славянских народов Сибири) актуальные научные проблемы, во многом еще до конца не решенные современной фольклористической мыслью. 
Можно с уверенностью сказать, что Г.С. Виноградов заложил теоретические основы так называемого «сравнительно-типологического» направления научных исследований в сибирской музыкальной фольклористике. Современное поколение ученых весьма плодотворно развивает научные идеи, сформулированные впервые в работах Г.С. Виноградова. В отдельных работах музыковедов Н.В. Леоновой, Л.В. Дёминой, Е.И. Жимулевой, Н.А. Урсеговой и других сибирских исследователей развитие идей Г.С. Виноградова ведется и в аспекте изучения процессов взаимодействия песенных фольклорных традиций восточнославянских народов (русских, украинцев, белорусов), их этнической и культурной интеграции.

Практическая апробация программы К. Квитки Г.С. Виноградовым состоялась в 1926 г., в общении с музыкантами Тункинского края (в 2о-е гг. $\mathrm{XX}$ в. административный центр Тункинского края - г. Иркутск, в настоящее время Тункинский район - это муниципальное образование (муниципальный район) в составе Республики Бурятия Российской Федерации). Результаты экспедиционной работы были опубликованы в журнале «Сибирская живая старина» в 1926 г. [4], где собиратель кратко описал местные музыкальные инструменты в исторической перспективе, технологические аспекты их изготовления, манеру игры на местных народных инструментах, исполняемый музыкальный репертуар. Кроме того, он знакомит читателей с конкретными именами мастеров и исполнителей, а также «ассоциациями» музыкантов, играющих группами и сольно на деревенских праздниках, свадьбах. Кроме того, что немаловажно, уточняет социальный статус тункинских музыкантов, дает их половозрастную характеристику. Г.С. Виноградов отмечает сохранность в крае «седой древней традиции, когда певец, приобыкший цитрою звонкой владеть, начинать песнопенье готовясь, строит ее, и упругие струны на ней, из овечьих свитые тонкотягучих кишек, без труда напрягает» [4, с. 39]. Речь здесь идет о сохранении в крае стародавней традиции игры на балалайке со струнами, которые вытягивали из бараньих жил и кишок, а не на современных фабричных «струнах из проволоки» (металлических).

В 1926 г. увидели свет нотные публикации песен и причитаний забайкальских старообрядцев, записанные еще в дореволюционные годы музыкально образованным любителем-собирателем Н.П. Протасовым, который по направлению Восточно-Сибирского отдела русского географического 
общества (далее - ВСОРГО) в І9ог г. работал в Забайкалье со старообрядцами в условиях их естественного бытования (проживания).

В статье «Как я записывал народные песни» Н.П. Протасов пишет: «Географическое Общество в Иркутске дало средства на поездку в Забайкалье, а для более точной записи мелодий был дан фонограф». Собиратель предполагал, что «досельная народная мелодия должна была сохраниться в наименее искаженном виде, так как старообрядцы, сосланные за Байкал в начале XVIII столетия и жившие отдельною общиною, были совершенно изолированы от всяких новшеств, надвинувшихся на Россию» [9, с. I33].

Здесь же Н. Протасов дает рекомендации по вопросу собирания музыкального фольклора, помещает ценные замечания о бытовании народной песни, констатирует факты исчезновения из активного репертуара староверов старинной песни. Через какие-нибудь го-2о лет от старой песни, по словам Н.П. Протасова, «останется одно грустное воспоминание». «Основываясь на личных наблюдениях, - писал собиратель, - приходится сознавать, что и здесь старая песня быстро начинает исчезать. Молодежь уже как будто стыдится старой песни и вместо таких богатых мелодий, как “Калинушка с малинушкой // Рано в поле расцвела” или “Долина ты моя долинушка, // Ничего ты не уродила”, предпочитает петь фабричную... или арестантскую песню...» [9, с. I35].

Известно, что Н.П. Протасов посетил 2I населенный пункт, где при помощи фонографа записал I45 мелодий: 9 духовных стихов, 8 причитей, I5 песен свадебных, 3 величальных, г обрядовых помочанских, 3 пасхальных, 3 троицких, 9 хороводных, І2 плясовых, 9 шуточных, 6о проголосных, 5 рекрутских, 5 арестантских, го солдатских [9, с. I35].

Часть материалов, записанных Н.П. Протасовым, была опубликована еще до революции, при жизни собирателя в г9о2 г. В нотном сборнике были напечатаны 20 народных песен Сибири (свадебные, хороводные, проголосные песни и свадебные причитания) для одного голоса с сопровождением фортепиано в переложении Алексея Петрова. Сборник был подготовлен по инициативе Песенной комиссии Императорского Русского географического общества и предназначен для «певцов-художников и любителей». В Комиссию песни, присланные Н.П. Протасовым, были достав- 
лены композитором Н.А. Римским-Корсаковым, а издан сборник по распоряжению композитора С.И. Танеева; средства на составление и издание песенных материалов были дарованы самим Государем Императором.

Еще одна небольшая часть собранных Н.П. Протасовым материалов была опубликована посмертно, в 1926 г. практически одномоментно в «Сибирской живой старине» [Іо] и в сборнике ВСОРГО [ІІ]: 9 нотных расшифровок одноголосных напевов духовных стихов, 7 текстов свадебной причети. Сам собиратель предполагал издать г26 мелодий с текстами, составил рукописный сборник. Однако большую часть своих записей он уничтожил, не добившись от ВСОРГО помощи в их издании [8, с. 82]. Также известно, что не сохранилась рукописная экспедиционная тетрадь Протасова и в иркутском архиве ВСОРГО.

Н.П. Протасов в процессе записи песен руководствовался принципами, которые во многом уже не приемлемы современной музыкальной фольклористикой: «Я старался записывать только те песни, которые, по моему крайнему разумению, были более древние и при этом обладали более богатым содержанием текста и музыкальных красот» [9, с. І35]. Можно предположить, что из-за такой произвольной фильтрации песенного материала много ценного было потеряно для науки. Записывая песни частично на фонограф, Н. Протасов использовал и слуховые записи, а также запись песен по памяти.

Кроме того, известно, что Н.П. Протасов не был профессиональным музыкантом, в связи с этим его нотировки довольно схематичны - песенные напевы нотированы в одноголосном изложении и, следовательно, не отражают сложнейшую многоголосную фактуру песен семейских Забайкалья, хорошо известные исследователям по более поздним (современным) фонозаписям. Нотировки песен в сборнике Н. Протасова содержат обычно одну зачинную строфу, а свойственная фольклорным образцам музыкальная вариативность (ритмическая, мелодическая, фактурная, а иногда и структурная) в процессе развития целостной музыкальной формы песни/ причитания не фиксируется.

Кроме того, редакционная коллегия сборника Н. Протасова в целях экономии места отказалась от публикации полных текстов песен, сохраняя только их начало. «Некоторым утешением при таком неисправном изложении служит то обстоятельство, что тексты почти половины духовных сти- 
хов сравнительно недавно были напечатаны А.М. Селищевым (он пользовался тетрадью Протасова) $)^{4}<\ldots>$ ».

Подобный подход в фиксации музыкально-фольклорного материала вполне свойственен так называемым ранним источникам. При современной повторной публикации дореволюционные записи подвергаются значительной текстологической доработке: ранние нотные источники печатаются в новой редакции, затрагивающей подтекстовку напевов, тактирование, синтаксическое ранжирование. В количественном отношении нотные записи многократно уступают записям словесных песенных текстов, что свидетельствует о сложности музыкальной фиксации фольклорно-этнографического песенного материала и недостаточной компетентности собирателей музыкального фольклора начала XX в.

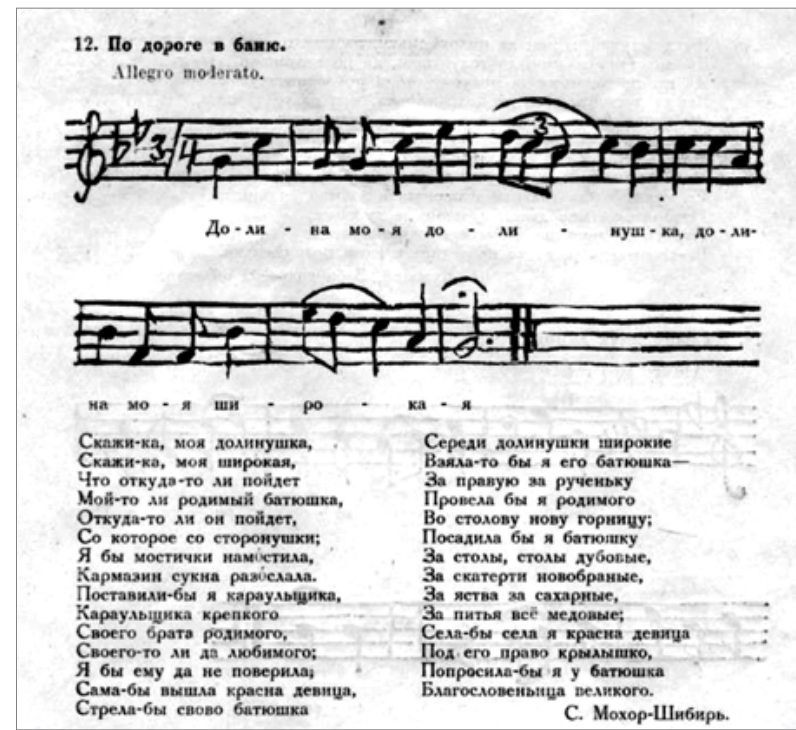

Пример 2 - «Скажи-ка, моя долинушка» [Іо, с. I3 $]^{5}$ Example 2 - "Tell me, my valley" [Io, p. I3]

В завершение статьи следует обозначить ее важнейшие итоги. Значительный хронологический отрезок времени, охватывающий период с I9I7

4 Селищев А.М. Забайкальские старообрядцы. Семейские / Изд-е Гос. Иркутского ун-та. Иркутск: Паровая тип. об-ва потребителей «Сибирское Книжное Дело», г920. 8I с.; 7 л. ил.

5 Помещена в разделе «Причеть свадебная». 
по I944 гг. - советский этап предыстории сибирской музыкальной фольклористики - не репрезентирует новых, равноценных дореволюционным, нотных собраний, за исключением единственной публикации - записей Н.П. Протасова, опубликованных в 1926 г., которые на самом деле относятся к дореволюционным. В изучаемый период времени публикуются единичные нотированные образцы песен сибирского бытования ${ }^{6}$ и обработки сибирских народных песен для голоса и фортепиано 7 . С фольклористической точки зрения избранный для изучения исторический период, особенно по сравнению с дореволюционным, оказался провальным.

Однако научная фольклористическая мысль изучаемого периода времени имеет большое историческое значение. В этой связи особую ценность представляет научно-теоретическая и практическая (собирательская) деятельность Г.С. Виноградова. В его работах закладываются теоретические основы современного, так называемого «сравнительно-типологического», направления научных исследований сибирских этномузыкологов-славянистов, формируются новые задачи и направления научной деятельности сибирской музыкальной фольклористики, которые продолжают свое развитие в современных исследованиях, посвященных изучению сложнейших процессов взаимодействия песенных фольклорных традиций восточнославянских народов, проживающих на территории Сибири.

Профессиональная позиция Г.С. Виноградова по вопросам собирания сведений о сибирских музыкантах и музыкальном исполнительстве при активном привлечении к этой работе этнографов, не имеющих специального музыкального образования, вызывает глубокое уважение и восхищение, а также большое желание воплотить его начинания в жизнь.

6 Две песни старого подполья. Записал Л. Шульгин // Музыка и революция. 1928. № 7-8; На взморье мы стояли [Сиб. напев]. Взвейтесь, соколы, орлами. Две старые солдатские песни. Томск, І943. 4 стр. с нот. (ВДНТ им. Н.К. Крупской); Сенкевич В. Песни сибирских партизан. Для одного голоса без сопровожд. М.: Музгиз, I935. VIII. 4 стр. (Песни гражд. войны).

7 Коваль М. Три русские народные песни для голоса с $\phi$-п. / ред. М. Иорданский; сост. М. Рудановская. М.: Изд-во Всес. упр. по охране авторских прав, І944. І9 с.; Мокроусов Б. Из-под камушка. Баллада. Для женск. голоса с $ф$-п. Текст народный, записан И. Коровкиным в г. Омске. М.: Музфонд СССР, І943. І2 с.; Прощай радость. Сиб. нар. песня. Для голоса и $\phi$-п. Гармонизация В.Г. Каратыгина. Л.: Тритон, г9зо. 8 стр. с нот. 


\section{Список литературы}

В[иноградов] Г. Новая программа по музыкальной этнографии // Сибирская живая старина. І925. Вып. III-IV. С. 388-390.

Виноградов Г.С. Этнография и современность // Сибирская живая старина. I923. № I. C. 3-2I.

3 Виноградов Г. Детский народный календарь (Из очерков по детской этнографии) // Сибирская живая старина. г924. Вып. II. С. 55-86. Виноградов Г.С. Из записей фольклориста. Музыканты в Тункинском крае // Сибирская живая старина. I926. Вып. I (V). С. 38-4I. Виноградов Г.С. Смерть и загробная жизнь в воззрениях русского старожилого населения Сибири // Восточная Сибирь. Тулуновский уезд. Иркутская губерния // Сб. трудов профессоров и преподавателей Иркутского государственного университета, І923. Вып. V. С. 26I-345.

6 Квитка К. Профессиональные народные певцы и музыканты на Украине (программа для исследования их деятельности и быта) // Квитка К. Избранные труды: в 2 т. М.: Сов. композитор, І973. Т. 2. С. 279-343.

7 Леонова Н.В. Из истории записи музыкального фольклора сибирских переселенцев // Вестник КемГУКИ. 20І1. № I7. С. 88-94.

8 Линьков А.И. Судьба бумаг Н.П. Протасова // Сибирский Архив. Журнал истории, археологии, этнографии Сибири, средней Азии и Дальнего Востока. Иркутск, I9I4. № 2. С. 82.

9 Протасов Н.П. Как я записывал народные песни // Известия ВСОРГО. І903. T. XXXIV. № 2. C. I3I-I36. Протасов Н.П. Песни забайкальских старообрядцев // Сибирская живая старина. I926. Вып. II (VI). С. 217-230 с нот. точн.-Сиб. отдела Гос. Русск. географ. Общества. І926. I6 с. с нот. Хромовских И.С. О народной песне // Сибирская живая старина. 1925. Вып. 3-4. C. 309 . 


\section{References}

I V[inogradov] G. Novaia programma po muzykal'noi etnografii [New program in musical ethnography]. Sibirskaia zhivaia starina, I925, vol. III-IV. pp. 388-390. (In Russ.)

2 Vinogradov G.S. Etnografiia i sovremennost' [Ethnography and modernity]. Sibirskaia zhivaia starina, I923, no I, pp. 3-2I. (In Russ.)

3 Vinogradov G. Detskii narodnyi kalendar' (Iz ocherkov po detskoi etnografii) [Children's folk calendar (From essays on children's ethnography)]. Sibirskaia zhivaia starina, I924, vol. II, pp. 55-86. (In Russ.)

4 Vinogradov G.S. Iz zapisei fol'klorista. Muzykanty v Tunkinskom krae [From the records of folklore. The musicians in the Tunka region]. Sibirskaia zhivaia starina, I926, vol. I (V), pp. 38-4I. (In Russ.)

5 Vinogradov G.S. Smert' i zagrobnaia zhizn' v vozzreniiakh russkogo starozhilogo naseleniia Sibiri [Death and afterlife in the views of the old Russian population of Siberia]. Vostochnaia Sibir'. Tulunovskii uezd. Irkutskaia guberniia. Sbornik trudov i professorov i prepodavatelei Irkutskogo gosudarstvennogo universiteta, I923, vol. V, pp. 26I-345. (In Russ.)

6 Kvitka K. Professional'nye narodnye pevtsy i muzykanty na Ukraine (programma dlia issledovaniia ikh deiatel'nosti i byta) [Professional folk singers and musicians in Ukraine (program for the study of their activities and life)]. Kvitka K. Izbrannye trudy: $v 2 t$. [Selected works: in 2 vols.] Moscow, Sovetskii kompozitor Publ.; I973, vol. 2, pp. 279-343. (In Russ.)

7 Leonova N.V. Iz istorii zapisi muzykal'nogo fol'klora sibirskikh pereselentsev [From the history of recording musical folklore of Siberian immigrants]. Vestnik KemGUKI, 20II, no I7, pp. 88-94. (In Russ.)

8 Lin'kov A.I. Sud'ba bumag N.P. Protasova [The fate of the papers by N.P. Protasov]. Sibirskiy Arkhiv. Zhurnal istorii, arkheologii, etnografii Sibiri, sredney Azii i Dal'nego Vostoka. Irkutsk, I9I4, no 2, p. 82. (In Russ.)

9 Protasov N.P. Kak ia zapisyval narodnye pesni [As I was writing down the folk songs]. Izvestiia VSORGO, I903, vol. XXXIV, no 2, pp. I3I-I36. (In Russ.)

IO Protasov N.P. Pesni zabaykal'skikh staroobryadtsev [Songs of the Old Believers of Transbaikal]. Sibirskaia zhivaia starina, I926, vol. II (VI), pp. 217-230. (In Russ.) Protasov N.P. Pesni zabaikal'skikh staroobriadtsev [Songs of the Old Believers of Transbaikal]. Irkutsk, Izd-vo Vostochn-Sib. otdela Gos. Russk. geograf. Obshchestva Publ., I926. I6 p. (In Russ.)

I2 Hromovskih I.S. O narodnoi pesne [About the folk song]. Sibirskaia zhivaia starina, I925, vol. 3-4, p. 309. (In Russ.) 